\title{
IMPLEMENTASI METODE COOPERATIF LEARNING TIPE JIGSAW PADA MATA PELAJARAN MATEMATIKA GUNA MENINGKATKAN HASIL BELAJAR SISWA KELAS V SD N WAWASAN
}

\author{
Marilin Kristina dan Ponidi *)
}

\begin{abstract}
Based on the results by preliminary observation about the low outcomes of grade V SDN Wawasan, the authors conducted a classroom action research to improve student learning outcomes. Collaborated with co-authors, writer tried to used Cooperative Learning Jigsaw Type in the first cycle learning, the second cycle, and the third cycle to improve class $V$ student achievement on SDN Wawasan. Improvement plan through this research was found using Jigsaw Cooperative learning model to improve student learning outcomes. From the evaluation results can be seen the increment in the percentage of student learning outcomes that can achieve minimum completeness criterion (KKM) obtained in the first cycle is $30.65 \%$, increased in the second cycle to $60 \%$, and $90 \%$ in the third cycle. Thus the author need to master and use various models of learning in every learning activity in the school.
\end{abstract}

Keyword: Cooperative Learning, Jigsaw, learning activity

\section{LATAR BELAKANG}

Pendidikan adalah usaha sadar untuk menyiapkan peserta didik melalui bimbingan, pengajaran, dan latihan bagi peranannya dimasa mendatang (UU Nomor 2 Tahun 1989 tentang Sisdiknas). Keberhasilan proses pembelajaran sebagai proses pendidikan di suatu sekolah dipengaruhi oleh banyak faktor. Faktor-faktor yang dimaksud misalnya guru, siswa, kurikulum, lingkungan sosial, dan lainlain. Namun dari faktor-faktor itu, guru dan siswa faktor terpenting. Pentingnya faktor guru dan siswa tersebut dapat dirunut melalui pemahaman hakikat pebelajaran, yakni sebagai usaha sadar guru untuk membantu siswa agar dapat belajar dengan kebutuhan minatnya.
Seorang guru harus berusaha memikul tanggung jawab besar terhadap pembelajaran khususnya kepada peserta didik demi meningkatkan pengetahuan dan hasil pengalaman belajarnya. Sebagai agen pembelajaran guru tidak hanya bertugas sebagai pengajar dan pendidik saja, tetapi harus pula memiliki kemampuan dalam memilih metode pembelajaran yang paling akomodatif dan kondusif untuk siswa, sehingga siswa dapat mengembangkan potensi yang dimilikinya secara efektif dan efisien.

Kenyataan yang sesungguhnya guru seringkali mendapat kendala bagaimana memilih dan menggunakan metode dalam pembelajaran, metode dan strategi yang 
bagaimana yang paling tepat untuk proses pembelajaran dikelas dan membahas satu materi pembelajaran, atau meningkatkan kreatifitas siswa. metode apakah yang paling diminati oleh Meningkatkan Hasil belajar siswa pada sebagian besar siswa, sehingga tercipta pelajaran Matematika dalam memahami sifatpembelajaran yang "PAIKEM GEMBROT" yaitu pembelajaran yang aktif, inovatif, kreatif, edukatif, menyenangkan, gembira dan berbobot.

Pembelajaran Matematika di Sekolah Dasar dapat dijadikan suatu landasan pengetahuan pada jenjang berikutnya.Pada umumnya siswa menganggap mata pelajaran Matematika merupakan mata pelajaran yang sangat sulit dipahami dan dimengerti, akibatnya tidak bersemangat dalam belajar sehingga nilai yang diperoleh tidak optimal.

Berdasarkan hasil observasi awal, nilai yang dicapai kelas V SDN Wawasan yang mencapai KKM 70 hanya 30,65\%. Meskipun telah dilakukan upaya, namun masih jauh dari harapan,dari 23 siswa yang mengikuti ulangan yang yang tuntas hanya 9 siswa, dan 14 siswa belum tuntas. Berdasarkan hasil observasi awal yang dilakukan peneliti menunjukkan pelajaran Matematika di SDN Wawasan masih menggunakan model pembelajaran konvensional yakni suatu model pembelajaran yang banyak didominasi oleh guru, sementara siswa duduk secara pasif menerima informasi.

Tujuan dari Pelaksanaan Perbaikan Pembelajaran melalui penelitian Tindakan kelas ini adalah untuk: (1) Memperbaiki sifat bangun datar. (3) Mendiskripsikan penerapan model pembelajaran cooperatif learning tipe jigsaw dalam pembelajaran matematika.

Cooperative Learning adalah salah satu model pembelajaran berbasis teori belajar sosial Robert Bandura yang dipopulerkan oleh Spencer Kagan, Robert Slavindan Johnson \&Johnson. Cooperative Learning adalah metode pembelajaran yang menekankan kepada proses kerjasama dalam suatu kelompok yang biasa terdiri dari 3 sampai 5 orang siswa untuk mempelajari suatu materi akademik yang spesifik sampai tuntas (Adang Heriawan, dkk, 2012:109).

Menurut Slavin (Isjoni, 2011:15) “In cooperative learning methods, students work together in four member teams to master material initially presented by the teacher". Berarti bahwa cooperative learning atau pembelajaran kooperatif adalah suatu model pembelajaran dimana sistem belajar dan bekerja kelompok-kelompok kecil berjumlah 4-6 orang secara kolaboratif sehingga dapat merangsang peserta didik lebih bergairah dalam belajar. Dari beberapa pengertian menurut para ahli dapat disimpulkan bahwa pembelajaran kooperatif adalah cara belajar dalam bentuk kelompok-kelompok kecil yang saling bekerjasama dan diarahkan oleh guru 
untuk mencapai tujuan pembelajaran yang diharapkan".

Menurut Johnson \& Johnson dalam Isjoni (2010:17) Cooperataive Learning adalah mengelompokkan siswa di dalam kelas ke dalam suatu kelompok kecil agar siswa dapat bekerja bersama dengan kemampuan maksimal yang mereka miliki dan mempelajari satu sama lain dalam kelompok tersebut. Ada beberapa metode dalam model pembelajaran Cooperative Learning diantaranya adalah:

1. Jigsaw

2. Student Team Achievement Division (STAD)

3. Team Game Tornament (TGT)

4. Number Head Together (NHT)

\section{Group Investigation}

6. Team Assisted Individualization (TAI)

Pembelajaran Kooperatif JIGSAW merupakan salah satu tipe pembelajaran kooperatif yang mendorong siswa aktif dan saling membantu dalam menguasai materi pelajaran untuk mencapai prestasi yang maksimal dengan cara membentuk tim ahli.

Metode ini terdapat tahap-tahap dalam penyelenggaraannya, yaitu:

1. Pembentukan kelompok siswa yang terdiri dari 4-6 orang, sebaiknya heterogen.

2. Setiap anggota kelompok ditugaskan untuk mempelajari materi tertentu.

3. Setiap anggota kelompok yang mempelajari materi yang sama bertemu dalamsatu kelompok baru membentuk 'Tim Ahli'. Selanjutnya materi tersebut didiskusikan, dipelajari apabila menemukan masalah dibahas bersama.

4. Setelah masing-masing perwakilan dalam tim ahli tersebut dapat menguasai materi yang ditugaskannya, kemudian masingmasing perwakilan tersebut kembali ke kelompok masing-masing atau kaelompok asalnya.

5. Masing-masing anggota tersebut saling menjelaskan kepada teman satu kelompoknya.sehingga teman dalam satu kelompoknya dapat memahami materi yang ditugaskan guru.

6. Siswa diberi tes/kuis untuk mengetahui apakah siswa sudah dapat memahami suatu materi atau belum.

Demikian melalui penyelenggaraan model Jigsaw dalam proses belajar mengajar dapat menumbuhkan tanggungjawab siswa sehingga terlibat langsung secara aktif dalam memahami suatu persoalan dan menyelesaikannya secara kelompok. Pada kegiatan ini keterlibatan guru dalam belajar mengajar semakin berkurang, dalam arti guru tidak lagi menjadi pusat kegiatan kelas. Guru berperan sebagai fasilitator yang mengarahkan dan memotivasi siswa untuk belajar mandiri serta menumbuhkan rasa tanggungjawab serta siswa akan merasa senang berdiskusi tentang materi pelajaran dalam kelompoknya. Metode Jigsaw sangat cocok untuk mata pelajaran Matematika. 


\section{METODE PENELITIAN}

Penelitian ini menggunakan metode deskriptif kuantitaif. Pada penelitian diskriptif kuantitatif, peneliti berusaha menggambarkan kegiatan penelitian yang dilakukan pada objek tertentu secara jelas dan sistematis (Sukardi, 2004:14). Penelitian deskriptif bertujuan untuk memberikan gambaran tentang suatu hubungan antara dua gejala atau lebih (Irawan Soehartono, 2008: $35)$.

Metode pengumpulan data

dilakukan dengan cara:

a. Dokumentasi

Metode dokumentasi yaitu mencari data mengenai berbagai hal yang menyangkut catatan, trankrip, majalah, notulen rapat, agenda, catatan nilai dan sebagainya. Dalam penelitian ini metode dokumentasi diambil dari catatan harian pembelajaran, catatan kolaborator (mitra penelitian), nilai siswa, maupun catatan perkembangan siswa dalam proses pembelajaran.

b. Observasi

Observasi yaitu pengamatan dengan menggunakan indera penglihatan. Metode observasi adalah cara-cara menganalisis dan mengadakan pencatatan secara sistematis mengenai tingkah laku dengan melihat atau mengamati individu atau kelompok secara langsung. Metode ini digunakan untuk melihat dan mengamati secara langsung keadaan di lapangan agar peneliti memperoleh gambaran yang lebih luas tentang permasalahan yang diteliti (Irawan Soehartono, 2008: 69).

Metode observasi dilaksanakan dengan cara melihat kegiatan belajar mengajar secara langsung yang berhubungan dengan penelitian. Observasi dilaksanakan di lingkungan sekolah pada saat pembelajaran Pendidikan Kewarganegaraan dilaksanakan. Observasi sangat membantu untuk dapat mempelajari perkembangan aktivitas siswa dan keterlibatan dalam proses pembelajaran

Pendidikan

Kewarganegaraan.

c. Tes

Metode tes digunakan untuk mengukur kemampuan siswa dalam menguasai materi pelajaran yang telah diberikan oleh guru. Metode tes dalam penelitian ini diberikan secara bertahap, setelah siswa mengikuti metode-metode pengajaran yang disampaikan oleh guru yang bersangkutan.

Instrumen pengumpulan data dilakukan dengan menggunakan indikatorindikator yang dapat mengukur partisipasi siswa dalam pembelajaran. Indikator tersebut kemudian digunakan oleh observer untuk menilai tingkat partisipasi. Prestasi belajar dinilai dari hasil evaluasi siswa dalam pembelajaran Pendidikan Kewarganegaraan. 
Secara terperinci instrumen penelitian menggunakan:

a) Lembar observasi siswa oleh kolaborator tentang aktivitas siswa.

b) Hasil evaluasi pembelajaran Pendidikan Kewarganegaraan.

c) Lembar observasi penilaian aktivitas guru pada saat proses belajar mengajar.

Teknik analisis data yang digunakan dalam penelitian ini adalah deskriptif kuantitatif. Data kuantitatif dianalisis dengan menguraikan fenomena yang terjadi di kelas serta mencari minimum skor mean, maksimal skor dan persentase pada prestasi belajar. Teknik analisis data dilaksanakan dengan proses reduksi data yang pada akhirnya mengarah pada suatu hasil kesimpulan yang merupakan hasil penelitian.

Rumus yang digunakan untuk menginterprestasi hasil analisis data adalah sebagai berikut:

$$
\mathrm{P}=\frac{\mathrm{F}}{\mathrm{N}} \times 100 \%=\cdots \%
$$

Keterangan:

$\mathrm{P}=$ Presentase

$\mathrm{F}=$ Sampel

$\mathrm{N}=$ Populasi

\section{HASIL DAN PEMBAHASAN}

Penelitian tindakan kelas dengan menerapkan metode cooperatif learning tipe jigsaw diharapkan nantinya dapat meningkatkan hasil belajar siswa pada mata pelajaran Matematika. Penelitian ini dilaksanakan di kelas V SDN Wawasan dengan jumlah siswa sebanyak 23 siswa. Prosedur penelitian terdiri dari empat komponen yaitu perencanaan, pelaksanaan atau tindakan, pengamatan, dan refleksi.

Setelah mengamati kegiatan belajar mengajar siswa belum efektif sehingga dalam penerapan metode cooperative learning tipe jigsaw siswa masih banyak yang asik mengobrol dan bermain sendiri dan dalam bekerjasama masih kurang. Maka guru perlu mengadakan perbaikan pada siklus II.

Hasil evaluasi siswa pada siklus I diperoleh sebagai berikut:

Tabel 2.1 Hasil evaluasi siswa

\begin{tabular}{|c|l|c|c|c|c|}
\hline \multirow{2}{*}{ No } & \multirow{2}{*}{ Nama Siswa } & \multirow{2}{*}{ Nilai } & \multicolumn{2}{|c|}{ Ketuntasan } & \multirow{2}{*}{ KKM } \\
\cline { 5 - 5 } & & & Tuntas & T.Tuntas & \\
\hline 1 & ANDIKA TRI ATMAJA & 75 & $\sqrt{ }$ & & 70 \\
\hline 2 & ANGGUN WIDYA SARI & 55 & & $\sqrt{ }$ & \\
\hline 3 & AULIA WARDIANTI P & 50 & & $\sqrt{ }$ & \\
\hline 4 & AYU RETNO NINGRUM & 30 & & $\sqrt{ }$ & \\
\hline 5 & DAFFA SAPUTRA & 50 & & $\sqrt{ }$ & \\
\hline 6 & DERA DARMAWAN & 55 & & $\sqrt{ }$ & \\
\hline 7 & FARID ABUNNASIR & 85 & $\sqrt{ }$ & & \\
\hline
\end{tabular}




\begin{tabular}{|c|l|c|c|c|c|}
\hline 8 & FARIZ FERDI ARDIANTO & 50 & & $\sqrt{ }$ & \\
\hline 9 & IRA SASKIA ZAHRA P. & 50 & & $\sqrt{ }$ & \\
\hline 10 & KINAYA WULANDARI & 45 & & $\sqrt{ }$ & \\
\hline 11 & KHINANTI RAMADHANI & 85 & $\sqrt{ }$ & & \\
\hline 12 & KHOLILA PUTRI R. & 90 & $\sqrt{ }$ & & \\
\hline 13 & REZI TEGUH SAFENDI & 40 & & $\sqrt{ }$ & \\
\hline 14 & RIDHO NANDA M. & 60 & & $\sqrt{ }$ & \\
\hline 15 & RIDWAN FADILAH & 70 & $\sqrt{ }$ & & \\
\hline 16 & SALSA NOVA AMELIA & 75 & $\sqrt{ }$ & & \\
\hline 17 & SATRIA ERLANGGA P. & 55 & & $\sqrt{ }$ & \\
\hline 18 & SYIFA ARUM ADELIA L. & 60 & & $\sqrt{ }$ & \\
\hline 19 & TRISTA MEI CHIKA M. & 50 & & $\sqrt{ }$ & \\
\hline 20 & VIDIA ANGGY S. & 75 & $\sqrt{ }$ & & \\
\hline 21 & WAHYU LANGIT OKTA R & 45 & & $\sqrt{ }$ & \\
\hline 22 & WIKE NURYANTI & 80 & $\sqrt{ }$ & & \\
\hline 23 & WULANDARI & 70 & $\sqrt{ }$ & & \\
\hline & Persentase & & $30,65 \%$ & $69,35 \%$ & \\
\hline Sim
\end{tabular}

Sumber : Hasil evaluasi pembelajaran

Dari hasil evaluasi yang tertera pada tabel 2, maka dari 9 dari 23 siswa atau $30,65 \%$ siswa telah tuntas dalam KKM yang berlaku di SDN Wawasan Kelas V untuk mata pelajaran Matematika dengan kompetensi dasar mengubah pecahan kebentuk persen dan desimal serta sebaliknya, dengan indikatornya mengubah pecahan biasa kepersen atau sebaliknya, yaitu 70, sedangkan 14 dari 23 siswa atau $69,35 \%$ siswa belum tuntas pada pembelajaran tersebut.

Setelah melihat dari hasil evaluasi maka perbaikan pembelajaran Matematika tentang mengubah pecahan kebentuk persen dan desimal serta sebaliknyadi kelas V SDN Wawasan masih kurang berhasil, maka penulis melakukan refleksi dengan mencari hal-hal apa saja yang harus dipersiapkan untuk melakukan untuk pembelajaran pada siklus II, tentu saja hal ini didiskusikan dahulu dengan teman sejawat dan supervisor 2 .

Penelitian pada siklus I harus dapat dijadikan acuan untuk meningkatkan hasil belajar siswa pada di disiklus II. Berkaitan dengan nilai yang didapat pada hasil evaluasi siswa pada siklus II diperoleh sebagai berikut: 
Tabel 2.3 Hasil evaluasi siswa

\begin{tabular}{|c|c|c|c|c|c|}
\hline \multirow{2}{*}{ No } & \multirow{2}{*}{ Nama Siswa } & \multirow{2}{*}{ Nilai } & \multicolumn{2}{|c|}{ Ketuntasan } & \multirow{2}{*}{$\begin{array}{c}\mathrm{KK} \\
\mathrm{M}\end{array}$} \\
\hline & & & Tuntas & T.Tuntas & \\
\hline 1 & ANDIKA TRI ATMAJA & 75 & $\sqrt{ }$ & & 70 \\
\hline 2 & ANGGUN WIDYA SARI & 65 & & $\sqrt{ }$ & \\
\hline 3 & AULIA WARDIANTI P & 60 & & $\sqrt{ }$ & \\
\hline 4 & AYU RETNO NINGRUM & 85 & $\sqrt{ }$ & & \\
\hline 5 & DAFFA SAPUTRA & 65 & & $\sqrt{ }$ & \\
\hline 6 & DERA DARMAWAN & 60 & & $\sqrt{ }$ & \\
\hline 7 & FARID ABUNNASIR & 80 & $\sqrt{ }$ & & \\
\hline 8 & FARIZ FERDI ARDIANTO & 65 & & $\sqrt{ }$ & \\
\hline 9 & IRA SASKIA ZAHRA P. & 80 & $\sqrt{ }$ & & \\
\hline 10 & KINAYA WULANDARI & 50 & & $\sqrt{ }$ & \\
\hline 11 & KHINANTI RAMADHANI & 85 & $\sqrt{ }$ & & \\
\hline 12 & KHOLILA PUTRI R. & 85 & $\sqrt{ }$ & & \\
\hline 13 & REZI TEGUH SAFENDI & 85 & $\sqrt{ }$ & & \\
\hline 14 & RIDHO NANDA M. & 80 & $\sqrt{ }$ & & \\
\hline 15 & RIDWAN FADILAH & 80 & $\sqrt{ }$ & & \\
\hline 16 & SALSA NOVA AMELIA & 80 & $\sqrt{ }$ & & \\
\hline 17 & SATRIA ERLANGGA P. & 50 & 7 & $\sqrt{ }$ & \\
\hline 18 & TRISTA MEI CHIKA M. & 85 & $\sqrt{ }$ & & \\
\hline 19 & VIDIA ANGGY S. & 100 & $\sqrt{ }$ & & \\
\hline 20 & WAHYU LANGIT OKTA R & 85 & $\sqrt{ }$ & & \\
\hline 21 & WISNU ALFIANSAH & 95 & $\sqrt{ }$ & & \\
\hline 22 & WIKE NURYANTI & 90 & $\sqrt{ }$ & & \\
\hline 23 & WULANDARI & 100 & $\sqrt{ }$ & & \\
\hline & Persentase & & $60 \%$ & $40 \%$ & \\
\hline
\end{tabular}

Sumber : Hasil evaluasi pembelajaran

Dari hasil evaluasi yang tertera pada tabel 2.4, maka dari 14 dari 23 siswa atau $60 \%$ siswa telah tuntas dalam KKM yaitu 70 yang berlaku di SDN Wawasan Kelas V untuk mata pelajaran Matematika dengan kompetensi dasar mengubah pecahan kebentuk persen dan desimal serta sebaliknya, dengan indikatornya mengubah pecahan biasa kepersen atau sebaliknya, sedangkan 9 dari
23 siswa atau $40 \%$ siswa belum tuntas pada pembelajaran tersebut.

Setelah melihat dari hasil evaluasi pada siklus II kegiatan pembelajaran siswa sudah mulai meningkat dan sudah ada koordinasi dengan metode yang diterapkan oleh guru.nilainya rata-rata naik menjadi $60 \%$, hasil dari pengamatan oleh guru kelas $\mathrm{V}$ dan penilai 2 penulis harus melakukan kembali dan memperbaikinnya, maka penulis 
disarankan untuk mengadakan penelitian jigsaw pada kelas $\mathrm{V}$ disiklus III, dapat pada siklus III.

dihasilkan nila yang berkaitan hdengan hasil

Adapun kegiatan pembelajaran dalam belajar siswa. Adapun hasil evaluasi siswa menerapkan metode cooperative learning tipe pada siklus III diperoleh sebagai berikut:

Tabel 2.5 Hasil evaluasi siswa

\begin{tabular}{|c|c|c|c|c|c|}
\hline \multirow{2}{*}{ No } & \multirow{2}{*}{ Nama Siswa } & \multirow{2}{*}{ Nilai } & \multicolumn{2}{|c|}{ Ketuntasan } & \multirow[t]{2}{*}{ KKM } \\
\hline & & & Tuntas & T.Tuntas & \\
\hline 1 & ANDIKA TRI ATMAJA & 100 & $\sqrt{ }$ & & 70 \\
\hline 2 & ANGGUN WIDYA SARI & 100 & $\sqrt{ }$ & & \\
\hline 3 & AULIA WARDIANTI P & 80 & $\sqrt{ }$ & & \\
\hline 4 & AYU RETNO NINGRUM & 100 & $\sqrt{ }$ & & \\
\hline 5 & DAFFA SAPUTRA & 90 & $\sqrt{ }$ & & \\
\hline 6 & DERA DARMAWAN & 85 & $\sqrt{ }$ & & \\
\hline 7 & FARID ABUNNASIR & 95 & $\sqrt{ }$ & & \\
\hline 8 & FARIZ FERDI ARDIANTO & 65 & & $\sqrt{ }$ & \\
\hline 9 & IRA SASKIA ZAHRA P. & 85 & $\sqrt{ }$ & & \\
\hline 10 & KINAYA WULANDARI & 90 & $\sqrt{ }$ & & \\
\hline 11 & KHINANTI RAMADHANI & 100 & $\sqrt{ }$ & & \\
\hline 12 & KHOLILA PUTRI R. & 100 & $\sqrt{ }$ & & \\
\hline 13 & REZI TEGUH SAFENDI & 90 & $\sqrt{ }$ & & \\
\hline 14 & RIDHO NANDA M. & 80 & $\sqrt{ }$ & & \\
\hline 15 & RIDWAN FADILAH & 95 & $\sqrt{ }$ & & \\
\hline 16 & SALSA NOVA AMELIA & 90 & $\sqrt{ }$ & & \\
\hline 17 & SATRIA ERLANGGA P. & 85 & $\sqrt{ }$ & & \\
\hline 18 & SYIFA ARUM ADELIA L. & 100 & $\sqrt{ }$ & & \\
\hline 19 & TRISTA MEI CHIKA M. & 100 & $\sqrt{ }$ & & \\
\hline 20 & VIDIA ANGGY S. & 90 & $\sqrt{ }$ & & \\
\hline 21 & WAHYU LANGIT OKTA R & 95 & $\sqrt{ }$ & & \\
\hline 22 & WIKE NURYANTI & 100 & $\sqrt{ }$ & & \\
\hline 23 & WULANDARI & 100 & $\sqrt{ }$ & & \\
\hline & Persentase & & $90 \%$ & $10 \%$ & \\
\hline
\end{tabular}

Sumber : Hasil evaluasi pembelajaran

Setelah melihat dari hasil evaluasi pada siklus III kegiatan pembelajaran siswa sudah meningkat dan sudah ada koordinasi dengan metode yang diterapkan oleh guru. Nilainya naik menjadi 90\%, maka penulis tidak melanjutkan perbaikan pelajaran berikutnya, karena hasilnya mencapai kriteria ketuntasan.

Dari hasil penelitian siklus I, II, III diperoleh hasil prosentase siswa dalam perbaikan penmbelajaran penulis 
menggunakan metode pembelajaran cooperative learning tipe jigsaw mengharapkan peningkatan hasil belajar siswa pada mata pelajaran Matematika di kelas V SDN Wawasan mencapai KKM yang diharapkan yaitu 70 .
Pada akhir pembelajaran penulis mengumpulkan hasil evaluasi siswa dan observasi dari guru kelas V sebagaii observer, dengan menggunakan metode pembelajaran cooperative learning tipe jigsaw hasilnya adalah:

Tabel 2.6 Prosentase Perbandingan Hasil belajar siswa

\begin{tabular}{|c|l|c|c|c|c|}
\hline No. & \multicolumn{1}{|c|}{ Nama Siswa } & $\begin{array}{c}\text { Siklus } \\
\text { I }\end{array}$ & $\begin{array}{c}\text { Siklus } \\
\text { II }\end{array}$ & $\begin{array}{c}\text { Siklus } \\
\text { III }\end{array}$ & Ket. \\
\hline 1 & ANDIKA TRI ATMAJA & 75 & 75 & 100 & Tuntas \\
\hline 2 & ANGGUN WIDYA SARI & 55 & 65 & 100 & Tuntas \\
\hline 3 & AULIA WARDIANTI P & 50 & 60 & 80 & Tuntas \\
\hline 4 & AYU RETNO NINGRUM & 30 & 85 & 100 & Tuntas \\
\hline 5 & DAFFA SAPUTRA & 50 & 65 & 90 & Tuntas \\
\hline 6 & DERA DARMAWAN & 55 & 60 & 85 & Tuntas \\
\hline 7 & FARID ABUNNASIR & 85 & 80 & 95 & Tuntas \\
\hline 8 & FARIZ FERDI ARDIANTO & 50 & 65 & 65 & Tidak Tuntas \\
\hline 9 & IRA SASKIA ZAHRA P. & 50 & 80 & 85 & Tuntas \\
\hline 10 & KINAYA WULANDARI & 45 & 50 & 90 & Tuntas \\
\hline 11 & KHINANTI RAMADHANI & 85 & 85 & 100 & Tuntas \\
\hline 12 & KHOLILA PUTRI R. & 90 & 85 & 100 & Tuntas \\
\hline 13 & REZI TEGUH SAFENDI & 40 & 85 & 90 & Tuntas \\
\hline 14 & RIDHO NANDA M. & 60 & 80 & 80 & Tuntas \\
\hline 15 & RIDWAN FADILAH & 70 & 80 & 95 & Tuntas \\
\hline 16 & SALSA NOVA AMELIA & 75 & 80 & 90 & Tuntas \\
\hline 17 & SATRIA ERLANGGA P. & 55 & 50 & 85 & Tuntas \\
\hline 18 & TRISTA MEI CHIKA M. & 60 & 85 & 100 & Tuntas \\
\hline 19 & VIDIA ANGGY S. & 50 & 100 & 100 & Tuntas \\
\hline 20 & WAHYU LANGIT OKTA R & 75 & 85 & 90 & Tuntas \\
\hline 21 & WISNU ALFIANSAH & 45 & 95 & 95 & Tuntas \\
\hline 22 & WIKE NURYANTI & 80 & 90 & 100 & Tuntas \\
\hline 23 & WULANDARI & 70 & 100 & 100 & Tuntas \\
\hline & & $30,65 \%$ & $60 \%$ & $90 \%$ & \\
\hline
\end{tabular}

Melihat tabel 2.6 di atas, maka dan desimal serta sebaliknya sudah 90\%, dan perbaikan pembelajaran pada siklus III hasil belajar yang diharapkan sudah dianggap berhasil karena ketuntasan semua meningkat. Hal ini dapat dilihat dalam siswa dalam pembelajaran matematika diagram perbandingan ketuntasan berikut ini tentang mengubah pecahan kebentuk persen 


\subsection{Grafik Perbandingan Ketuntasan Siklus I,II dan III}

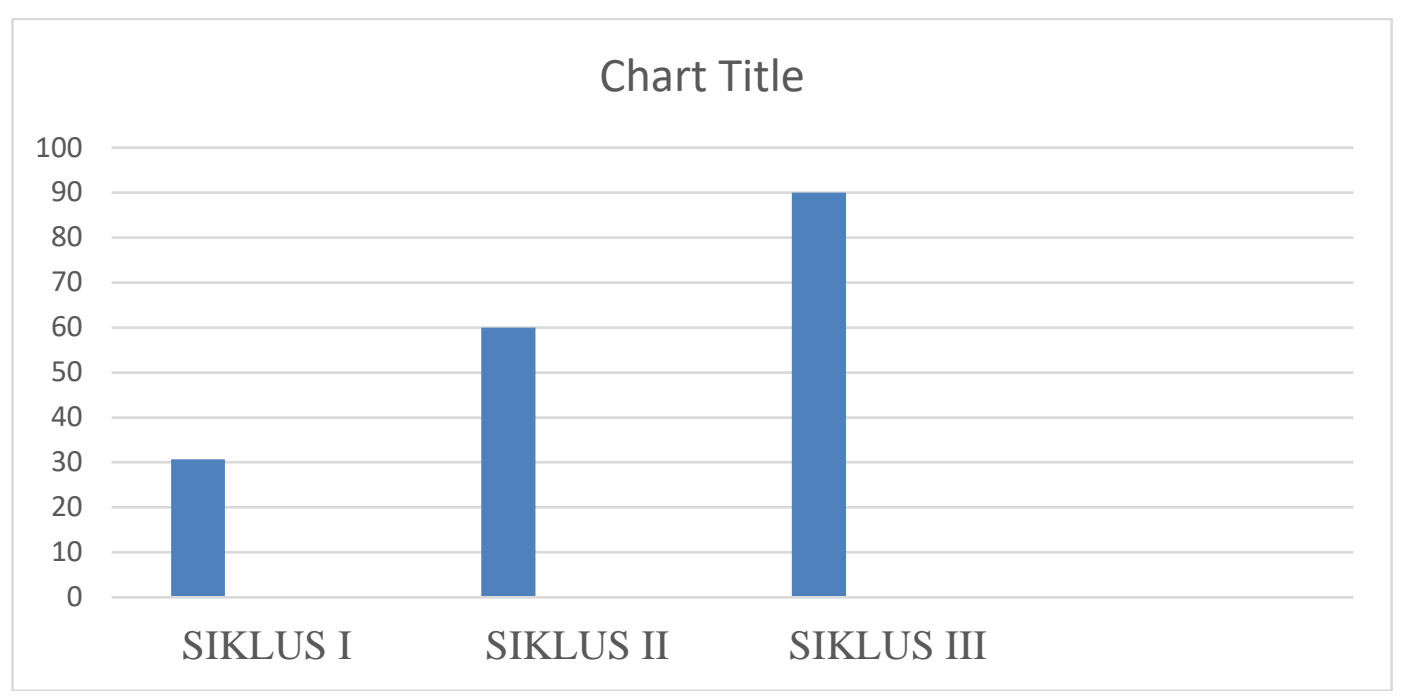

Berdasarkan diagram tersebut terlihat bahwa dalam penggunaan metode cooperative learning tipe jigsaw dapat meningkatkan hasil belajar siswa kelas $\mathrm{V}$ SDN Wawasan, dimulai dariSiklus I, II dan III telah sukses membawa siswa mengubah pecahan kebentuk persen dan desimal serta sebaliknya. Maka untuk selanjutnya demi keberhasilan pembelajaran maka seorang guru harus selalu melakukan dan merumuskan PTK sehingga dapat meningkatkan profesionalisme seorang guru.

\section{SIMPULAN DAN SARAN}

\section{Simpulan}

1. Penggunaan metode cooperative learning tipe jigsaw melalui diskusi dapat meningkatkan hasil belajar siswa, karena mereka termotivasi mengikuti pembelajaran sehingga materi yang disampaikan dapat diterima dengan baik.
2. Peningkatan hasil belajar siswa kelas V SDN Wawasan dapat di lihar dari adanya perubahan nilai yang didapat dimasingmasing siklus. Adapun perubahan nilai tersebut yaitu pada siklus I siswa yang tuntas dalam belajar mencapai 30,65\% dari siswa yang berjumlah 23 siswa, dan mengaalami kenaikan pada siklus II dengan mencapai $60 \%$ dari jumlah siswa 23, dan pada siklus III mengalami kenaikan yang sangat signifikan yaitu mencapai $90 \%$ dari 23 siswa

3. Dalam proses pembelajaran Matematika kelas V SDN Wawasan pada siklus I dan II Kurang kondusif. Banyak permasalahan yang mengganggu proses pembelajaran sehingga tujuan yang ingin dicapai kurang memuaskan. Sedangkan pada proses pembelajaran pada siklus III berjalan dengan kondusif sehingga tujuan yang diharapkan bias tercapai. 


\section{Saran}

Berdasarkan kesimpulan diatas maka peneliti menyarankan hal-hal sebagai berikut:

1. Bagi Guru

a. Menggunakan metode yang tepat sesuai dengan tujuan pembelajaran dan kemampuan siswa yang belajar.

b. Menggunakan lebih dari satu atau dua metode pembelajaran, karena setiap metode mempunyai kelemahan dan kelebihan.

c. Penyampaian materi Mengubah pecahan kebentuk persen dan decimal dan sebaliknya akan lebih baik jika menggunakan metode cooperative learning tipe jigsaw, sebab penggunaan metode tersebut akan memotivasi siswa mengikuti pelajaran, sehingga hasil dan aktivitas belajarnya maksimal. Hal ini telah terbukti di kelas V SD Negeri Wawasan pada matapelajaran Matematika.

2. Bagi siswa diharapkan dalam pembelajaran selalu menanyakan masalah-masalah yang tidak dipahami dan dimengerti pada materi yang diajarkan dan melakukan diskusi dengan temannya dalam menyelesaikan masalah.

\section{DAFTAR PUSTAKA}

Adang Heriawan, dkk. (2012). Cooperative Learning Teori \& Aplikasi Paikem. Yogyakarta: PustakaPelajar.

Anneahera (2011) "In cooperative learning methods, students work together in four member teams to master material initially presented by the teacher"

Irawan Soehartono. (2008). Metode penelitian sosial. Bandung: Remaja Rosdakarya.

Isjoni. (2011). Cooperative Learning Efektivitas Pembelajaran Kelompok. Bandung: Alfabeta.

Made Wena. (2009). Strategi pembelajaran inovatif kontemporer. Jakarta: Bumi Aksara.

Slameto. (2005). Motivasi belajar dan faktorfaktor yang mempengaruhinya. Jakarta: Rineka Cipta.

Sujono Hamzah. (2003). Belajar Matematika. Yogyakarta: Andi ofset.

Sukardi. (2004). Metodologi penelitian pendidikan. Jakarta: Bumi Aksara.

Sumarno, Alim. (2011). Pengertian Hasil Belajar, (http://elearning. unesa.ac.id/tag/teori-hasil-belajargagne-dan-driscoll-dalam-bukuapa). Diakses 20 April 2018.

Uno. (2011). Media Pembelajaran. Jakarta: Rajawali Pers.

Destiana Vidya Prastiwi. (2010). Belajar dan Pembelajaran. Bandung: Penerbit. 